\title{
Development of measures to improve the operating conditions of the Teshiktash hydroelectric complex in Uzbekistan
}

\author{
Panjiev Sherzod
}

\begin{abstract}
The purpose of the work is to assess the reliability and risk analysis of accidents of reservoir structures, as well as the development of measures to improve the operating conditions of the structures of the Teshiktash hydroelectric complex. Research focus on Teshiktash hydroelectric complex: spillway dam, water intake facilities as a case study.
\end{abstract}

Index Terms - water resources, agriculture hydroelectricity, Teshiktash complex, Uzbekistan

\section{INTRODUCTION}

Brief description of the structures of the Teshiktash hydroelectric complex and topic

The Teshiktash waterworks is located on the Karadarya River in the Pakhtaabad district of the Andijan region. It is At 46 kilometers below the Andijan reservoir dam near the village of Teshiktashadyra on the right and left banks of the Karadarya river, the valley of the river narrows to $1.5 \mathrm{~km}$. Above Teshiktash, the Kugartsay flows into the Karadarya River from the right with the tributary Changetsay and the Karagunon to the left, and spring water flows out of the Karadarya flood plain. This place, due to favorable conditions, has long been used for water intake into irrigation canals.

Until 1938 water intake was carried off with spurs. Then a ryazhe barrage was built, but the wide front of the barrage and the underestimated threshold did not stop the wandering of the river and the dam of the structure with sediments. For several years the water intake was carried out again with the help of spiny spurs. And only at the end of the 50s (1956-1960) the Teshiktash concrete water retaining dam was constructed with the water intake structures of the Pakhtabad, Upper Ulugnar and Asronkulbek canals providing irrigation, respectively, 17130, 9023 and 500 hectares. In 2002, on the right bank, $25 \mathrm{~m}$ above the Asronkulbek water outlet, a water outlet was built to feed the Pakhtaabad canal at a flow rate of $10 \mathrm{~m} 3$ / $\mathrm{s}$. The maximum throughput capacity of the Teshiktash waterworks is $1450 \mathrm{~m} 3 / \mathrm{s}$ at the water horizon in the upper reach of $657.80 \mathrm{~m}$. The working water horizon in the upstream is $655.30 \mathrm{~m}$.

And only at the end of the 50s (1956-1960) the Teshiktash concrete water retaining dam was constructed with the water intake structures of the Pakhtabad, Upper Ulugnar and Asronkulbek canals providing irrigation, respectively, 17130, 9023 and 500 hectares. In 2002, on the right bank, $25 \mathrm{~m}$ above the Asronkulbek water outlet, a water outlet was built to feed the Pakhtaabad canal at a flow rate of $10 \mathrm{~m} 3 / \mathrm{s}$. The maximum throughput capacity of the Teshiktash waterworks is $1450 \mathrm{~m} 3 / \mathrm{s}$ at the water horizon in the upper reach of $657.80 \mathrm{~m}$. The working water horizon in the upstream is $655.30 \mathrm{~m}$.

The groundwater level in the upper and lower pools of the hydroelectric complex is close to the surface of the base of the dams and varies according to the fluctuation of the water level in the river and canals. Visual observations in the upstream are marked by active channel processes (re-formation, sediment deposition), in the downstream are erosion of the channel. The middle spans of the dam work to discharge mainly during the flood period. it is included by order of the Ministry of Agriculture and water resources No. 125 dated 05.19.1994. to the list of especially important, which are subject to additional requirements for reliability and ensuring normal operating conditions.

\section{Observed river flow: \\ - maximum - 780m3 / s; \\ - minimum - 40m3 / s.}

The grounds of the dam base are a conglomerate on sandy cement. The floodplain of the river is composed of gravel-pebble sediments.
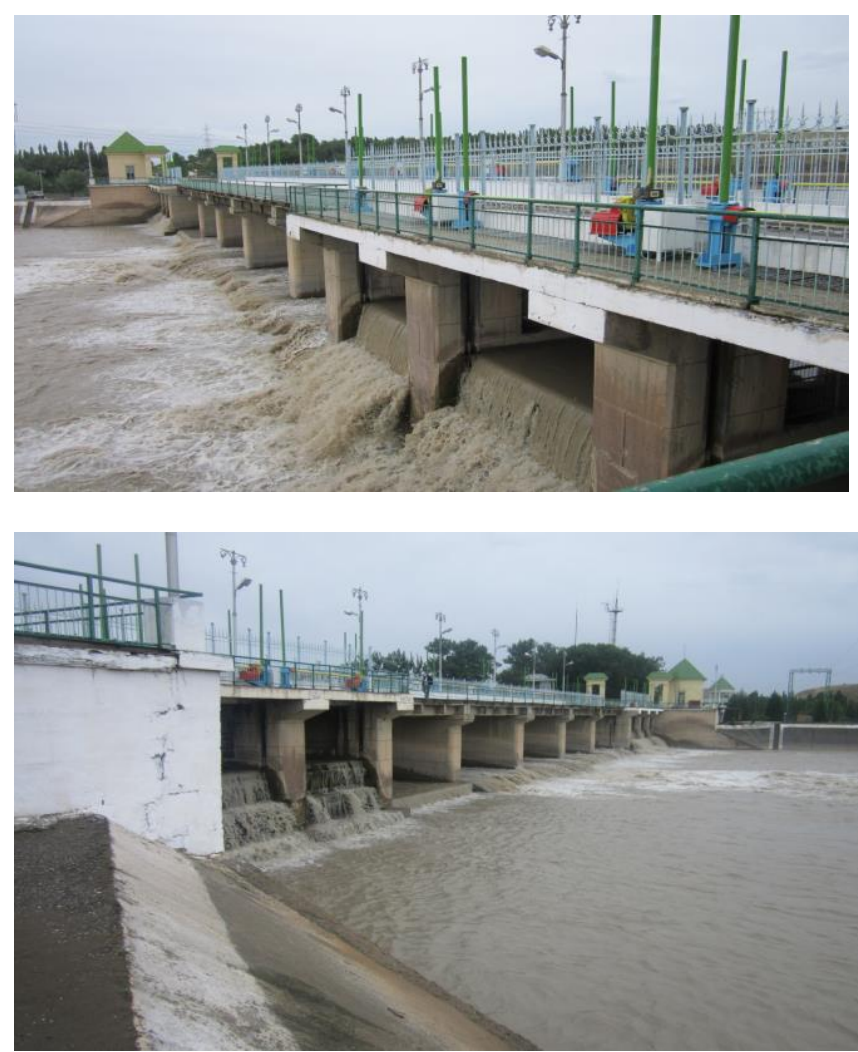
Safety criteria for hydraulic structures are the limiting values of quantitative and qualitative indicators of the state of hydraulic structures and their operating conditions corresponding to the acceptable risk level of an accident of a hydraulic structure and approved in the prescribed manner by the federal executive bodies exercising state supervision of safety of hydraulic structures.

Safety of hydraulic structures - state of hydraulic structures, allowing to ensure the protection of life, health and legitimate interests of people, the environment and economic objects Assessment of safety of a hydraulic structure - determination of compliance of the state of a hydraulic structure and the qualifications of employees of the operating organization with the norms and rules approved in the manner defined by the law "On safety of hydraulic structures".

Monitored indicators - measured at this facility with the help of technical means or quantitative characteristics calculated on the basis of measurements, as well as qualitative characteristics of the state of the GTS.

Operational condition of the facility:

normal - the condition of the structure, in which the structure meets all the requirements of regulatory documents and the project, while the values of the diagnostic indicators of the state of the structure do not exceed their criterion values of $\mathrm{K} 1$;

potentially dangerous - a condition in which the value of at least one diagnostic indicator has become greater (smaller) than its first (warning) level of criteria values (K1 values) or has gone beyond the range of values predicted by this combination of loads.

The potentially dangerous condition of the structure does not meet the regulatory requirements, but the operation of the hydraulic structures does not lead to the threat of an immediate breakthrough of the pressure front and the structure can be operated for a limited time;

pre-emergency - a condition in which the value of at least one diagnostic indicator has become greater (smaller) than the second (limit) level of criterion values (K2 value). In this case, operation of the structure in design modes is unacceptable without the express permission of the supervisory authority.

\section{METHODOLGY}

The direct use of probabilistic methods in calculating the reliability and safety of hydraulic structures was begun by the works of Ts. E. Mirtskhulava and was further developed in the works of V.I. Velitchenko, G.A. Vorob'eva, G.K. Gabrichidze, T.V. Gavrilenko, E.G. Gazieva.

Issues of probabilistic analysis of the reliability and safety of hydraulic structures were considered in the ICOLD committees, at international congresses, conferences, symposia, in foreign periodicals. Various problems of environmental and social security, including in hydrotechnical construction, were solved in different years by A. B. Avakyan, N.A. Alekseev, V.A. Anikeev, V.V. Anikeev, G.A.Bachinsky, K.M. Berkovich, A.G. Vasilevsky, Yu.S.Vasilyev, S.L.Vendrov, E.V.Girusov.

The work of I. Klima, O. Laricheva, E. Musik, P. Muller, C. Starra and others, who systematized and outlined the main ways to solve them, is devoted to accounting for uncertainty and risk factors in solving safety problems in engineering and environmental management. He formulated the basic requirement of environmental and social security: the gradual introduction of a rational environmental management system designed to ensure the economical exploitation of natural resources and the conditions for their effective reproduction while preserving elements of social stability - people's life and health, minimizing environmental and social losses. Nevertheless, despite the achievements in the field of analysis of hydraulic structures for reliability and safety, currently there is no single approach to solving the problem, which would be linked to the methods and approaches of the modern theory of reliability and risk theory.

And it would allow the development of probabilistic methods for analyzing the reliability and safety of various hydraulic structures taking into account the peculiarities of their design, construction and operation, type, design, properties, nature of impact on humans and the environment, from a unified methodological standpoint.

In particular, the experience of solving probabilistic problems of assessing the reliability and safety of hydraulic structures suggests that often even the choice of the calculation method for these objects is difficult due to the following main reasons:

a) Hydrotechnical objects can unite a large number of various kinds of constructive, functional, and calculating system units, the reliability and safety of objects in general depend on the operability and operability of each of them. However, the representation of hydraulic structures in the form of systems and the construction of models of reliability of such systems causes significant difficulties because hydraulic structures initially do not have a pronounced network structure, and the nature of the interaction between structural and functional units in the sense of reliability is much more complicated than the simplified series-parallel schemes. In addition, the design elements of hydraulic structures, often conditional, may allow different degrees of formalization with varying representativeness of the initial information about their condition. The development of systems analysis methods, the adaptation of existing methods and approaches of the system theory of reliability, as applied to hydraulic structures, is one of the most important tasks requiring its solution.

b) The methods and approaches of the parametric theory of the reliability of structures, structures and bases, as well as the method of limit states, allow us to approach the assessment of the reliability of an object only by certain criteria of reliability and safety. Attempts to take into account the interdependence of various criteria for the reliability and safety of hydraulic structures within the framework of the parametric theory extremely complicates the task, since the processes determining the state of hydraulic structures, as well as the permissible areas of their states, are described by a large number of parameters, which is why the corresponding equations may not have a strict analytical decision. The proposed methods in the framework of the theories of multidimensional distributions, correlation functions, recognition of convoy, etc. provide only purely theoretical possibilities for solving the problem. In practice, this is due to the use of very complex calculation procedures and, most importantly, the lack of, as a rule, the required initial information, an increase in the level of its uncertainty as insufficiently verified data are used, etc. At the same time, simplified parametric reliability models and security can provide fairly objective assessments with significantly less 
time and money. The transition from simplified calculation methods to more accurate calculations is desirable, but with the accumulation of relevant data on probabilistic characteristics of loads, indicators of material and soil properties, parameters of hydraulic structures, their structures and bases, elements and equipment, indicators of the environment, changes in design characteristics in time, etc.

c) The development of hydraulic structures as a result of the action of so many factors that all of them cannot be taken into account analytically, and rigorous mathematical predictions are possible only for a limited time interval compared with the service life of the objects. And some of the factors are fundamentally random, and sometimes indefinite. At the same time, there is always the risk of missing or neglecting one or another factor. Therefore, in the calculations we can talk more about some constant comparison of options for ensuring the reliability and safety of hydraulic structures in order to select the least "risky" from possible solutions.

d) Reliability and safety of hydraulic structures should be considered in technical, economic, environmental and social aspects. To ensure reliable and safe operation of hydraulic structures, an analysis of the full range of impacts that affect the objects and a comprehensive assessment of the effects of hydraulic structures on the environment are necessary. The final goal, which should be the selection of parameters of hydraulic structures and operating modes of hydraulic structures that are safe for the population and natural structures, the development of appropriate environmental protection measures, etc.

e) The introduction of a probabilistic approach to risk assessment for the safety of hydraulic structures requires a clear coordination in environmental and ecological organizations, local governments and nomenclature administrations, signs of the socio-ecological well-being of territories and standardization of criteria for technical, environmental and social security of hydraulic structures. Since the changing operating conditions, the socio-economic and ecological environment affects the reliability and safety of hydraulic structures.

\section{FAUlt Tree AnAlysis (FTA)}

Fault Tree Analys is a deductive method for determining conditions and factors that can lead to a certain undesirable event (the so-called head event). A "fault tree" is a logically organized graphical design that demonstrates the interaction of system elements whose failure, either individually or in combination, may contribute to the appearance of an undesirable event - the failure of the system as a whole the head event of the "failure tree". determining the head event (for groundwater dams and dams, this may be overflowing a ridge, loss of stability, filtration strength, for spillway structures - failure of valves, etc.). Possible physical events and processes that can lead to the main event form the first level of the "failure tree" that follows it. At the second level, events, phenomena and processes that can cause failures of the first level of the "failure tree" are defined, at the third level - the second level, etc.

The step-by-step movement along all possible paths of undesirable functioning of the structure from the upper level to the lower leads, thus, to the level of failures of the elements of the hydraulic structures and its equipment - the so-called basic failures. Events and processes at each level are associated with those for the next level of the "failure tree" by logical operators of the type "AND", "OR", etc. When constructing "failure trees", event symbols are used, which are listed in Table 1.1. The conditional notation for logical operators is given in Table. 1.2.

If there are representative data (statistics, passports, etc.) on the intensity of the basic failures, the "failure tree" can be solved, i.e., the average annual frequency (probability) of the head event realization on the base failure frequencies events and phenomena that can lead to the main event of the "failure tree". It should be borne in mind that the elements of the "failure tree" can be events associated not only with failures of the hydraulic structures and equipment elements, but also with operational errors, design, construction, surveys, as well as external natural and man-made impacts (over-calculated flood, rainfall, seismic impact, terrorist act, etc.). With the representative data of the numerical values of the probabilities of basic failures, it is possible to obtain a quantitative estimate of the average annual frequency of the head event of an accident of a specific CTA.

As sources of information to obtain information about the average annual frequencies of basic failures, reference, regulatory, literary publications and publications in the field of risk analysis and assessment of the level of safety of hydraulic structures and their elements, as well as information of the data banks on accidents of hydraulic structures can be used.

It should be noted that the analysis of the "fault tree" can be used not only to determine the frequency (probability) of the head event, but also to determine the frequency of events at any level of the "fault tree", which is an undoubted advantage of the method in its applications to hydraulic structures, The branches of the "failure trees" for different head events coincide.

The analysis of the "fault tree" gives the group of executors the opportunity to build a logical model of the occurrence and development of processes and phenomena leading to a GTS accident, and this model provides both qualitative and quantitative information about the safety of a structure and the level of risk of accidents on it. The disadvantage of the method is its laboriousness and considerable difficulties in verifying the adequacy of the constructed graphs to real processes capable of initiating accidents of the analyzed structure.

The undoubted advantages of the method of analyzing the "fault tree", widely used in various industries and already beginning to be applied in the field of hydraulic engineering, include the possibility of identifying those aspects of the work of a structure that are of great importance for ensuring its safety; presentation to specialists working not only in the field of hydraulic engineering, but also in other fields of knowledge related to ensuring the safety of hydraulic structures (insurers, sociologists, rescuers, etc.), visual graphical information about the ways in which the emergence and development of emergency processes in the analyzed structure; the possibility of carrying out both qualitative and quantitative risk analysis of accidents of hydraulic structures; possibility of a detailed analysis of certain types and methods of structures failures 
Table 1.1

\begin{tabular}{|c|c|}
\hline Event designation & Event \\
\hline & Event Developed \\
\hline & Event condition \\
\hline & Carry symbol \\
\hline
\end{tabular}

Table 1.2

Symbols of logical operators

\begin{tabular}{|c|l|l|}
\hline $\begin{array}{c}\text { Operator } \\
\text { designation }\end{array}$ & $\begin{array}{l}\text { Operator } \\
\text { Name }\end{array}$ & $\begin{array}{l}\text { The causal relationship, } \\
\text { expressed by the operator }\end{array}$ \\
\hline or & «or» & $\begin{array}{l}\text { Event-consequence takes place } \\
\text { when at least one of the } \\
\text { initiating events occurs }\end{array}$ \\
\hline $\begin{array}{c}\text { or } \\
\text { exceptio } \\
\text { nal }\end{array}$ & $\begin{array}{l}\text { «or } \\
\text { exceptional» }\end{array}$ & $\begin{array}{l}\text { Event-consequence takes place } \\
\text { when at least one of the } \\
\text { initiating events occurs }\end{array}$ \\
\hline and & «and» & $\begin{array}{l}\text { Event-consequence takes place } \\
\text { at the onset of all initiating } \\
\text { events }\end{array}$ \\
\hline th & «tfrom n» & $\begin{array}{l}\text { The event occurs when any of } \\
\text { the initiating events occurs }\end{array}$ \\
\hline Tr & «condition» & $\begin{array}{l}\text { The onset of the event-effect is } \\
\text { possible upon the occurrence of } \\
\text { the event-condition }\end{array}$ \\
\hline
\end{tabular}

Evaluation of the reliability of hydraulic structures of the hydraulic system.

The decision of the "failure tree" is made according to the following formulas

Scenario A1 - Technical failure of water intake structures

$$
\begin{gathered}
P_{A 1}=P_{B 1} \cdot P_{B 2} ; \\
P_{B 1}=1-\left(1-P_{C 1}\right) \cdot\left(1-P_{C 2}\right) \cdot\left(1-P_{C 3}\right) \cdot\left(1-P_{C 4}\right) ; \\
P_{B 2}=1-\left(1-P_{C 1}\right) \cdot\left(1-P_{C 2}\right) \cdot\left(1-P_{C 3}\right)
\end{gathered}
$$

Scenario A2 - Technical failure of a water supply dam

$$
\begin{gathered}
P_{A 2}=P_{B 1} \cdot P_{B 2} P_{B 3} P_{B 4} \\
P_{B 1}=1-\left(1-P_{C 1}\right) \cdot\left(1-P_{C 2}\right) \cdot\left(1-P_{C 3}\right) \cdot\left(1-P_{C 4}\right) ; \\
P_{B 2}=1-\left(1-P_{C 1}\right) \cdot\left(1-P_{C 2}\right) \cdot\left(1-P_{C 3}\right) \\
P_{B 3}=1-\left(1-P_{C 1}\right) \cdot\left(1-P_{C 2}\right) \cdot\left(1-P_{C 3}\right) \\
P_{B 4}=1-\left(1-P_{C 1}\right) \cdot\left(1-P_{C 2}\right) \cdot\left(1-P_{C 3}\right)
\end{gathered}
$$

The numerical values of the expected average annual frequencies of the realization of events - elements of the "failure trees" - were determined according to the project, according to published information sources, according to field data.
For scenario A1

$$
P_{A 1}=10^{-6} 1 / \text { year }
$$

For scenario $\mathrm{A}_{2}$

$$
P_{A 2}=10^{-4} 1 / \text { year }
$$

The generalized risk of the implementation of the limit state of the first group for class I water-engineering facilities in the period of continuous operation allowed by the norms is (4-5) 10-4 1 / year. A comparison of these values with those obtained by calculation makes it possible to consider the risk of accidents at the Teshiktash hydroelectric station and the safety level of the hydraulic structures in general meets the standards. However, given the significant magnitude of the consequences of accidents at the hydroelectric complex, it is recommended to develop measures to improve the safety level of the hydro technical station

\section{RESULTS}

As a result of the survey of the hydro system and the verification of the necessary documents, the following were revealed:

Dam:

- slopes of dams in the upper reach have cracks, destruction of concrete lining, voids under the lining. In the left-bank dam places of reinforcement are bare Shield concrete dam:

- there is destruction of the steel lining of the bottom metal plates.

Right Bank Regulator Pakhtaabad

- the hull of the gearboxes of the lifting mechanisms have fractures, cracks

Right-bank channel regulator Asronkulbek

- see notes on all regulators of the waterworks. Right bank regulator feed channel Pakhtaabad

- no defects found.

On all regulators of the waterworks:

- the teeth of the cargo nut gearboxes constantly wear out. Restoring them by welding does not give the desired effect.

- there is filtering through the side and bottom seals of the valves;

Observations of filtration regime and deformations of structures

There is no piezometric network (the project provides for the installation of 23 observation wells and piezometers, "Instrumentation at the waterworks of the Andijan region". Working draft. Association "VODPROEKT" of the Ministry of Agriculture and Mineral Resources of the Republic of Uzbekistan. Tashkent 1966); Information about the implementation of observations of the deformations of the structures of the waterworks until 2000 is not available. In 2000, the Diagnostic Center "Gosvodkhoznadzor" made a bookmark KIA and produced a zero cycle of planned-altitude observations. The following cycles of observations were not performed. For these reasons, it is not possible to make a conclusion on the state of the waterworks facilities based on field observations. 


\section{CONCLUSION}

We could say that at least the followings can be done:

a) restore the concrete facing of the slope of the left bank straightening dam;

b) restore the metal cladding of the floor of the dam's culvert; perform the reconstruction of mechanical equipment according to a project developed by the Institute "Uzgiprovodkhoz" (RP "Replacement of obsolete machinery and metal structures of the Teshiktash hydroelectric complex in the Andijan region");

on the valves, in the places of the most filtration, replace "P" -shaped rubber seals;

c) have on the water-engineering unit backup electric motors, a stock of lifting gear parts most susceptible to wear of the gearbox (gears, cargo nuts), lifting screws. Continue on-site observations of the deformations of the structures by geodetic methods, install observation wells and piezometers according to the project to study the filtration regime of groundwater

Based on the work done on the study of the technical condition of the Teshiktash hydroelectric complex, the following conclusions can be drawn:

- analyzed existing methods for assessing the reliability of hydraulic structures;

- defects and deficiencies in the operation of the waterworks structures were studied;

- scenarios of the risk of hydroelectric station accidents were compiled;

- The reliability of hydraulic structures of the water-engineering complex was evaluated;

- developed measures to improve the reliability of operation of the waterworks;

- Concrete proposals are given to improve the working conditions for the operation of the facilities of the Teshiktash hydroelectric complex.

\section{REFERENCE}

[1] The Law of the Republic of Uzbekistan "On the safety of hydraulic structures". Tashkent 1999

[2]Bakiev MR, Tursunov T.N., Durmatov J. Organizing exploitation services in water providing organizations. TIMI Irrigation Hydro Engineering and usage, Bulletins of Resolution No. 1.2. Toshkent, 2006, 21 pages

[3] Kaveshnikov N.T. Maintenance and repair of hydraulic structures M. Agropromizdat, 1980, $272 \mathrm{p}$

[4]Methods for determining the criteria for the safety of hydraulic structures. RAO "UES of Russia", M. 2000, 18 p.

[5]Typical operating instructions for reservoirs for irrigation needs, with a capacity of up to 10 million m3. M., 1982.

[6] Typovy rules for the operation of reservoirs with a capacity of 10 million m3 and more. RD 33-3. 02.08-87. Ed. official. M., 1987.

[7]Veksler AB, Ivashintsov DA, Stefenishin D.V. Reliability, social and environmental safety of hydraulic facilities: risk assessment and decision making. Www. Vniig.ru/ru/cooperation.ru 